\title{
Papillary Thyroid Carcinoma: Analysis of the Central Compartment's Lymph Nodes Metastases
}

\author{
Ján Sojak ${ }^{1,2,3, *}$, Marian Sičák ${ }^{1}$, Adrian Kališ̌ ${ }^{5}$ Michal Slaštan ${ }^{4}$
}

\begin{abstract}
Background: Papillary thyroid carcinoma is typical by regional lymph nodes metastases. Therefore we decided to analyse associated risk factors. Objective: In this retrospective study we focused on the incidence of metastatic involvement of the central compartment's lymph nodes correlated with age, size of the primary tumour, infiltration of thyroid gland capsule, positive lymphangioinvasion in order to assess risk factors. Method: We analysed group of 156 patients with papillary carcinoma, who have undergone total thyroidectomy and bilateral elective central compartment neck dissection. We evaluated the occurrence of metastases, size, infiltration and lymphangioinvasion based on definitive histology of the whole group and separately for subgroups of patients under and over 45 years. Result: We found metastatic involvement in 88 (56.4\%) patients. When comparing the subgroups of patients under ( 73 patients) and over 45 years ( 83 patients), we found metastases in 56 vs. 32 (76.7\% vs. 38.6\%) patients. In the subgroup of younger patients we found significant higher incidence of metastases compared with the group of over 45 years, $P<0.001(P=0.000027)$. We found significant higher incidence of metastases in patients with positive capsule infiltration in the whole group, $P<0.001(P=0.00049)$; in the subgroup of under 45 years, $P<0.001$ $(P=0.00091)$ and in patients with positive lymphangioinvasion in the whole group, $P<0.01(P=0.00177)$; in the subgroup of over 45 years, $P<0.001(P=0.0002)$. In patients with metastases we found tumour size $\geq 1 \mathrm{~cm}$ more frequently in all groups. Conclusion: We recorded higher incidence of regional metastases in patients under 45 years, positive capsule infiltration, lymphangioinvasion. Age under 45 years itself does not correlate with less aggressive disease, to the contrary some of other analysed risk factors correlate with more aggressive disease.
\end{abstract}

\section{KEYWORDS}

papillary carcinoma; thyroid gland; metastases; regional lymph nodes; age

\section{AUTHOR AFFILIATIONS}

${ }^{1}$ Slovak Medical University in Bratislava, Faculty of Medicine, The Clinic of Otorhinolaryngology and Head and Neck Surgery, Central Military Hospital in Ružomberok, Slovakia

${ }^{2}$ Comenius University in Bratislava, Jessenius Faculty of Medicine in Martin (JFM CU), Department of Pathological Physiology JFM CU, Slovakia

${ }^{3}$ Biomedical Centre Martin JFM CU, Slovakia

${ }^{4}$ Department of Medical Biochemistry JFM CU, Slovakia

${ }^{5}$ Catholic University in Ružomberok, Faculty of Health, Department of Pathological Anatomy, Central Military Hospital in Ružomberok, Slovakia

* Correspondence author: Klinika ORL a CHHaK, Ústredná vojenská nemocnica SNP-FN, Ul. gen. Miloša Vesela 21, 03401 Ružomberok, Slovakia; e-mail: jansojak@gmail.com

Received: 25 November 2016

Accepted: 20 December 2016

Published online: 1 June 2017

Acta Medica (Hradec Králové) 2017; 60(1): 44-50

https://doi.org/10.14712/18059694.2017.49

(c) 2017 The Authors. This is an open-access article distributed under the terms of the Creative Commons Attribution License (http://creativecommons.org/licenses/by/4.0), which permits unrestricted use, distribution, and reproduction in any medium, provided the original author and source are credited. 


\section{INTRODUCTION}

Papillary thyroid carcinoma (PTC) and its variants belong to the group of differentiated thyroid carcinomas and to the most common oncological disease of the thyroid gland (1). To stage PTC we use the TNM classification (Table 1), where patients younger than 45 years without remote metastases (MO) belong to the stage I regardless of the $\mathrm{T}$ and $\mathrm{N}(2)$.

Tab. 1: TNM classification - staging (2).

\begin{tabular}{|l|l|l|l|l|}
\hline \multicolumn{4}{|l|}{ Papillary or follicular carcinoma, patient under 45 years } \\
\hline Stage I & any T & any N & M0 \\
\hline Stage II & any T & any N & M1 \\
\hline Papillary or follicular carcinoma, patient above 45 years \\
\hline Stage I & T1 & N0 & M0 \\
\hline Stage II & T2 & N0 & M0 \\
\hline Stage III & T3 & N0 & M0 \\
\hline & T1, T2, T3 & N1a & M0 \\
\hline Stage IV A & T1, T2, T3 & N1b & M0 \\
\hline & T4a & N0, N1 & M0 \\
\hline Stage IV B & T4b & any N & M0 \\
\hline Stage IV C & any T & any N & M1 \\
\hline
\end{tabular}

$\mathrm{T} 1$ - tumour $\leq 2 \mathrm{~cm}$, intraglandular; $\mathrm{T} 2$ - tumour $>2$ to $4 \mathrm{~cm}$, intraglandular; T3 - tumour > 4cm or limited spread; T4a - skin, larynx, trachea, oesophagus or nervus laryngeus recurrens infiltration; $\mathrm{T} 4 \mathrm{~b}$ - prevertebral fascia, mediastinal vessels or arteria carotis infiltration; NO - without metastases in regional lymph nodes; $\mathrm{N} 1 \mathrm{a}$ - metastases in region $\mathrm{Vl} ; \mathrm{N} 1 \mathrm{~b}$ - metastases in other regions; $\mathrm{MO}$ - no remote metastases; $\mathrm{M} 1$ - remote metastases

Mortality in patients with PTC ranges from 1.2 to $17 \%$; the average five-year survival in PTC limited to the thyroid gland tissue is $99.7 \%$, in case of metastases into regional lymph nodes (LN) $96.9 \%$, and with remote metastases $57.8 \%$ (3); the average ten-year survival is between 85 to 99\% (4) and drops with increasing tumour size and extrathyroid growth (5). Some papers point to higher risk of nodal recurrence, worse prognosis and increase of risk of death by $46 \%$ related to occurrence of regional LN metastases $(3,6)$.

Regional LN metastases are found in $20-80 \%$ patients ( $56.4 \%$ in the whole group of our patients). The central compartment (region VI) is involved with a frequency reaching $90 \%$ including micro metastases $(1,3,4)$; less frequently are affected areas III, IV and rarely areas II and V (7). Persistence and recurrence of PTC are influenced by regional LN metastatic involvement, size of the primary tumour, extracapsular growth, and remote metastases. Persistence and recurrence of the illness decrease average survival independently from the age of patients and decrease quality of life by more radical and repeated surgical interventions and oncological treatment with radioactive iodine and external radiotherapy $(1,8,9)$.

The aim of this study was to analyse the incidence of metastatic involvement of central compartment LN correlated to the age limit of 45 years.

\section{MATERIAL AND METHODS}

We performed a retrospective analysis of collected archived data obtained from 336 patients suffering from PTC (out of which 276 cases were the conventional variant, in 44 cases the follicular variant and in 16 cases oncocytary variant of PTC; 259 females and 77 males) who had surgery at our clinic during the time frame of 2003 till 2015. These patients underwent a standard diagnostic and therapeutic procedure which was not affected by this study. Patients signed an informed consent allowing us to analyse all collected personal and medical data.

Included in the group, there were patients meeting the following inclusion criteria: The patient underwent a model of initial surgical therapy - lobectomy on the side of the suspected carcinoma with intraoperative biopsy (frozen section). In case of a positive finding of PTC from intraoperative biopsy surgery was finished with total thyroidectomy and a bilateral elective central compartment neck dissection (level VI) regardless of age. In case of a negative finding in the intraoperative biopsy, the surgery was finished as a lobectomy; with positive finding of PTC in definite biopsy following the lobectomy a reoperation was performed within 6 weeks of the primary surgery - finished total thyroidectomy and a bilateral elective central compartment neck dissection regardless of age. Selective neck dissection of LN groups in levels I, II, III, IV, V was only performed if deemed necessary by individual case with clinical suspicion of regional metastasizing $(\mathrm{cN}+)$ to those cervical levels (Table 2). None of the patients underwent any forms of adjuvant therapy as this therapy was implied only post-surgery by an endocrinologist. Patients who have met the following exclusion criteria are not included (in spite of a positive find of PTC in intraoperative and/or definite histology) - patient has not undergone total thyroidectomy, has not undergone bilateral elective central compartment neck dissection, underwent only unilateral elective central compartment neck dissection, has not undergone neck dissection, relevant data was not available, patient underwent surgery in a different way than that described in inclusion criteria.

156 patients met the criteria with histologically verified PTC, who underwent total thyroidectomy and bilateral neck dissection of regional LN in minimal range of bilateral elective central compartment neck dissection. This group has been divided by the age limit 45 years (using by TNM classification) into a subgroup of patients under 45 years (73 patients) and a subgroup of patients over 45 years (83 patients). Only $46.4 \%$ of patients with pathologically verified carcinomas met the inclusion criteria. The most frequent unmet inclusion criterion was above described unmet model of initial surgical therapy (total thyroidectomy and a bilateral elective central compartment neck dissection regardless of age). The reason dwells in fact that this model has been applied at our clinic gradually, e.g. in years 2003, 2005, 2007 it has not been applied in any of the patients, in years 2004, 2006, 2008 it was applied only in one patient per year, and yet, for instance, in year 2015 there were already 24 patients subjected to this initial surgery model. 
Tab. 2: Patients after total thyroidectomy and bilateral neck dissection.

\begin{tabular}{|l|l|l|l|}
\hline Range of surgical intervention & All patients $\mathbf{( N = 1 5 6 )}$ & Under 45 $\mathbf{y . ~ ( N ~ = ~ 7 3 ) ~}$ & Over 45 y. (N = 83) \\
\hline TTE + bilateral central compartment ND & $\mathbf{n}(\mathbf{\%})$ & $\mathbf{n}(\mathbf{\%})$ & $\mathbf{n}(\%)$ \\
\hline $\begin{array}{l}\text { TTE + bilateral central compartment ND + } \\
\text { unilateral selective ND }\end{array}$ & $29(18.6)$ & $55(75.3)$ & $65(78.3)$ \\
\hline $\begin{array}{l}\text { TTE + bilateral central compartment ND + } \\
\text { bilateral selective ND }\end{array}$ & $7(4.5)$ & $14(19.2)$ & $15(18.1)$ \\
\hline
\end{tabular}

$\mathrm{n}$ - number of patients, \% - relative percentage, $\mathrm{N}$ - number of patients in the whole group, TTE - total thyroidectomy, ND - neck dissection

Tab. 3: Histologically verified metastatic involvement of regional lymph nodes.

\begin{tabular}{|l|l|l|l|}
\hline Regional lymph nodes metastases & All patients $\mathbf{( N = 1 5 6 )}$ & Under 45 y. $(\mathbf{N}=\mathbf{7 3})$ & Over 45 y. $(\mathbf{N}=\mathbf{8 3})$ \\
\hline Positive metastases & $\mathbf{n}(\mathbf{\%})$ & $\mathbf{n}(\mathbf{\%})$ & $\mathbf{n}(\mathbf{\%})$ \\
\hline - Positive metastases unilateral & $88(56.4)$ & $56(76.7)$ & $32(38.6)$ \\
\hline - Positive metastases bilateral & $52(33.3)$ & $34(46.6)$ & $18(21.7)$ \\
\hline Negative metastases & $36(23.1)$ & $22(30.1)$ & $14(16.9)$ \\
\hline
\end{tabular}

$\mathrm{n}$ - number of patients, \% - relative percentage, $\mathrm{N}$ - number of patients in the whole group

In a group of patients who underwent preoperative ultrasonography, a suspicious lymphadenopathy $(\mathrm{cN}+)$ was diagnosed in $29 \%$, however based on the definitive histology we have confirmed regional LN metastases on the level of 56.4\%. Sensitivity of preoperative fine needle aspiration biopsy (FNAB) at our workplace equalling to $94.7 \%$ and sensitivity of intraoperative biopsy equalling to $89.7 \%$. Incidence of after surgery complications was not for this particular group patients evaluated due to the missing data, however as far as our department is concerned there was not higher risk in connection with thyroid surgery noted. Due to the lower percentage of suspicious lymphadenopathy identified by the preoperative ultrasonography examination and high incidence of regional LN metastases verified by definitive histology we consider the elective central neck dissection in case of histological confirmed PTC as reasonable.

Based on definitive histology we evaluated the occurrence of metastases in central compartment LN, size of the primary tumour, infiltration of thyroid gland capsule and lymphangioinvasion for the whole group, and separately for both subgroups defined by age. As positive metastatic involvement we assessed the case of at least one LN metastasis in central compartment verified by definitive histology, while the size of the LN metastasis was not taken into consideration. It is not relevant whether the positive histology is from the primary intervention or reoperation (within 6 weeks of the primary surgery).

This study is limited by certain factors, which could be potentially removed by planning of a prospective study that would specify the exact definition of studied criteria. What I mean is unreliable, improper or missing data and information concerning size and the exact number of me- tastases, precise measurement of thyroid gland capsule infiltration, and precise analysis of affection levels I.-V. Histological findings were evaluated by different pathologists and surgeries performed by various surgeons in a long time period. We are missing the exact information regarding the occurrence of complications. A more precise post-surgery follow up, documentation of possible recurrences, remote metastases, process of complications as well as adjuvant therapy used is needed. These are missing due to the fact that the post-surgery aftercare in our region is managed by endocrinologist. We would also need correlation of the LN metastases incidence and increased risk of local recurrences and death. Due to the long survival in PTC, long term survival data is needed.

The results were interpreted using relative quantity and one-dimensional chi-quadrate test with Yates correction on the level of significance 0.01 and 0.001 (software Statistica 8).

\section{RESULTS}

\section{METASTATIC INVOLVEMENT IN REGIONAL LYMPH NODES}

In our group of 156 patients with PTC, who underwent total thyroidectomy and bilateral neck dissection of regional LN in minimal range of bilateral elective central compartment neck dissection, we evaluated metastatic involvement based on definitive histological study of the central compartment LN. The information concerning metastatic involvement of LN was available in $100 \%$ of the patients. We evaluated the whole group, the subgroup under 45 years and the subgroup of patients over 45 years (Table 3 ). 
Tab. 4: Size of primary tumour.

\begin{tabular}{|l|l|l|l|}
\hline Size of primary tumour & All patients $(\mathbf{N}=\mathbf{1 5 0})$ & Under $\mathbf{4 5} \mathbf{y .}(\mathbf{N}=\mathbf{7 2})$ & Over $\mathbf{4 5} \mathbf{y}(\mathbf{N}=\mathbf{7 8})$ \\
\hline $\begin{array}{l}\text { No. of patients in the whole group } \\
\text { (156 patients) }\end{array}$ & $\mathbf{n}(\%)$ & $\mathbf{n}(\%)$ & $\mathbf{n}(\%)$ \\
\hline Tumour size $<1 \mathrm{~cm}$ & $59(39.3)$ & $24(33.3)$ & $35(44.9)$ \\
\hline Tumour size $\geq 1 \mathrm{~cm}$ & $91(60.7)$ & $48(66.7)$ & $43(55.1)$ \\
\hline Tumour size undetermined & 6 & 1 & 5 \\
\hline
\end{tabular}

\begin{tabular}{|l|l|l|l|}
\hline Patients with $\mathrm{MTS}-\mathrm{pN}+$ & $84(56)$ & $55(76.4)$ & $29(37.2)$ \\
\hline Tumour size $<1 \mathrm{~cm}, \mathrm{pN}+$ & $31(20.7)$ & $17(23.6)$ & $14(17.9)$ \\
\hline Tumour size $\geq 1 \mathrm{~cm}, \mathrm{pN}+$ & $53(35.3)$ & $38(52.8)$ & $15(19.2)$ \\
\hline Tumour size undetermined, pN+ & 4 & 1 & 3 \\
\hline
\end{tabular}

\begin{tabular}{|l|l|l|l|}
\hline Patients without MTS - pNO & $66(44)$ & $17(23.6)$ & $49(62.8)$ \\
\hline Tumour size $<1 \mathrm{~cm}, \mathrm{pNO}$ & $28(18.7)$ & $7(9.7)$ & $21(26.9)$ \\
\hline Tumour size $\geq 1 \mathrm{~cm}, \mathrm{pNO}$ & $38(25.3)$ & $10(13.9)$ & $28(35.9)$ \\
\hline Tumour size undetermined, pN0 & 2 & 0 & 2 \\
\hline
\end{tabular}

$\mathrm{n}$ - number of patients, $\%$ - relative percentage, $\mathrm{N}$ - number of patients in the evaluated group, MTS - metastatic involvement, pN+ - histologically verified metastases in regional lymph nodes, pNO - histologically verified status without metastases in regional lymph nodes

Comparing the subgroups of under 45 years and over 45 years we found metastatic involvement in $76.7 \%$ vs. $38.6 \%$ patients. In the subgroup of under 45 years we found on the level of statistical significance 0.001 higher incidence of metastatic involvement of central compartment LN when compared to patients over 45 years, $\mathrm{P}<0.001(\mathrm{P}=0.000027)$.

\section{SIZE OF THE PRIMARY TUMOUR}

We evaluated the tumour size $<1 \mathrm{~cm}$ and $\geq 1 \mathrm{~cm}$ based on the results of the histology. We made the evaluation for the group of all patients, the group of under 45 years, the group of over 45 years, correlated to metastatic involvement as well (Table 4). The information about the tumour size was available in 150 patients $(96.2 \%)$.

During statistical analysis we have not found statistically significant higher incidence of metastatic involvement linked with tumour size $\geq 1 \mathrm{~cm}$ in the group of all patients $(\mathrm{P}=0.604)$; in the subgroup of patients under 45 years $(P=0.62)$; in the subgroup of patients over 45 years $(P=0.818)$. However, in patients with verified metastatic involvement we have found the size of tumour $\geq 1 \mathrm{~cm}$ more frequently in all groups.

INFILTRATION OF THE CAPSULE OF THYROID GLAND We evaluated the groups for infiltration of the capsule based on the histological finding, whereas even the finding of limited focal thyroid gland capsule infiltration without extrathyroid spreading was regarded as positive case. The evaluation was done for the whole group of patients, for the subgroup of under 45 years, and for the subgroup of over 45 years, correlated to metastatic involvement (Table 5). The information was available in 151 patients (96.8\%).
During the statistical evaluation we noted on a level of statistical significance 0.001 in patients with positive infiltration of thyroid gland capsule more frequent metastatic involvement and in patients with negative infiltration less frequent metastatic involvement in the whole group of patients, $\mathrm{P}<0.001(\mathrm{P}=0.00049)$ and in the group of patients under 45 years $\mathrm{P}<0.001(\mathrm{P}=0.00091)$. In the group of patients over 45 years we haven't found significantly more frequent metastatic involvement with positive infiltration of thyroid gland capsule $(\mathrm{P}=0.146)$.

\section{LYMPHANGIOINVASION}

Based on the definitive histological examination and findings we have evaluated the presence of lymphangioinvasion. The evaluation was done for the whole group, for the subgroup of under 45 years of age and for the subgroup over 45 years, correlated to metastatic involvement (Table 6). The information concerning lymphangioinvasion was available in 142 (91\%) patients.

During statistical evaluation we found on levels of statistical significance 0.01 a 0.001 patients with positive lymphangioinvasion more frequent metastatic involvement and in patients without lymphangioinvasion less frequent metastatic involvement in the group of all patients, $\mathrm{P}<0.01(\mathrm{P}=0.00177)$ and in the subgroup of over 45 years, $\mathrm{P}<0.001(\mathrm{P}=0.0002)$. In the subgroup of patients under 45 years of age we have not found significantly more frequent metastatic involvement with positive lymphangioinvasion $(\mathrm{P}=0.085)$. 
Tab. 5: Thyroid gland capsule infiltration.

\begin{tabular}{|l|l|l|l|}
\hline Capsule infiltration & All patients $(\mathbf{N}=\mathbf{1 5 1})$ & Under $\mathbf{4 5} \mathbf{y} \cdot \mathbf{( N = 7 1 )}$ & Over 45 y. (N = 80) \\
\hline $\begin{array}{l}\text { No. of patients in the whole group } \\
\text { (156 patients) }\end{array}$ & $\mathbf{n}(\%)$ & $\mathbf{n}(\%)$ & $\mathbf{n}(\%)$ \\
\hline Capsule infiltration positive & $107(70.9)$ & $53(74.6)$ & $54(67.5)$ \\
\hline Capsule infiltration negative & $44(29.1)$ & $18(25.4)$ & $26(32.5)$ \\
\hline Capsule infiltration undetermined & 5 & 2 & 3 \\
\hline
\end{tabular}

\begin{tabular}{|l|l|l|l|}
\hline Patients with MTS $-\mathrm{pN}+$ & $83(55)$ & $54(76.1)$ & $29(36.3)$ \\
\hline Capsule infiltration positive, pN+ & $69(45.7)$ & $46(64.8)$ & $23(28.8)$ \\
\hline Capsule infiltration negative, pN+ & $14(9.3)$ & $8(11.3)$ & $6(7.5)$ \\
\hline Capsule infiltration undeterm., pN+ & 5 & 2 & 3 \\
\hline
\end{tabular}

\begin{tabular}{|l|l|l|l|}
\hline Patients without MTS - pNO & $68(45)$ & $17(23.9)$ & $51(63.8)$ \\
\hline Capsule infiltration positive, pNO & $38(25.2)$ & $7(9.9)$ & $31(38.8)$ \\
\hline Capsule infiltration negative, pNO & $30(19.9)$ & $10(14.1)$ & $20(25)$ \\
\hline Capsule infiltration undeterm., pNO & 0 & 0 & 0 \\
\hline
\end{tabular}

$\mathrm{n}$ - number of patients, $\%$ - relative percentage, $\mathrm{N}$ - number of patients in the evaluated group, MTS - metastatic involvement, $\mathrm{pN}+-$ histologically verified metastases in regional lymph nodes, pNO - histologically verified status without metastases in regional lymph nodes

\section{DISCUSSION}

The aim of this study was to analyse the incidence of metastatic involvement of the central compartment LN correlated to the age limit of 45 years. We also analysed size of primary tumour, infiltration of thyroid gland capsule and lymphangioinvasion in order to evaluate these relevant risk factors. Our intention is to offer an impulse to analyse surgical approaches and re-evaluate their effect with the emphasis on younger patients whereas age under 45 years in our study does not correlate with less aggressive disease and we regard to use age itself as an independent risk factor to be controversial.

The frequency of metastatic involvement of regional LN in patients under 45 years in our study reached $76.7 \%$ (in all patients $56.4 \%$; in patients over 45 years $38.6 \%$ ). In our previous study we analysed metastatic involvement also in the whole cohort of our 336 patients with PTC regardless of model of initial surgical therapy. We found frequency of metastatic involvement of regional LN in $54.1 \%$ of patients under 45 years (in $37.8 \%$ of all patients; in $26.9 \%$ of patients over 45 years) (10). It also proves that the bilateral elective central compartment neck dissection increased in our collection frequency of metastasis verification in all groups of patients.

It is a matter to consider when thinking about the TNM staging, which in age group of patients younger than 45 years seemingly ignores the fact that the presence of metastases in regional LN can influence the rate of persistence, recurrence of the illness and quality of life.

For patients suffering from PTC is typical long term survival and the evaluation of the outcomes of treatment algorithms and surgical approaches is time consuming. Opinions about benefits of different surgical approaches are controversial, especially about effect of elective central compartment neck dissection. Patients have a comparable ten-year survival with no regard to the scale of surgical treatment, this fact advocate the tendency of implementing limited surgical intervention and caution in more radical intervention indication $(5,11)$, but the incidence of regional LN metastases on the level of $56.4 \%$ in the whole group and as high as $74.6 \%$ in the group of under 45 years makes us rethink the possibility of performing total thyroidectomy and elective central compartment neck dissection as a standard surgical procedure in patients with positive intraoperative or definite histology. Some authors do not considered lobectomy itself to be an adequate primary radical intervention in patients with verified PTC because it is bound to a higher risk of local recurrence, contralateral lobe malignity development in case of multifocal occurrence and this risk is higher in tumours $\geq 1 \mathrm{~cm}$, regardless of age $(1,5)$. The lobectomy also deprives the patients of the possibility of adjuvant oncological treatment, monitoring (body scan, serum Tg measurement) and it increases the risk of revision (1).

It is suitable to take into account regardless of the long term survival also the quality of life of patients which is influenced by possibility of persistence, recurrence, generalization, the need for repeated surgical and radioiodine therapeutic procedures. If standard surgical approaches are maintained, a percentage of complications is low even in bigger scale primary interventions $(5,12)$, contrariwise long term complications after the reoperation can be twice as high as after the primary intervention $(5,13)$. When 
Tab. 6: Lymphangioinvasion.

\begin{tabular}{|l|l|l|l|}
\hline Lymphangioinvasion & All patients $\mathbf{N}=\mathbf{1 4 2})$ & Under $\mathbf{4 5} \mathbf{y .}(\mathbf{N}=\mathbf{6 6})$ & Over 45 y. (N = 76) \\
\hline $\begin{array}{l}\text { No. of patients in the whole group } \\
\text { (156 patients) }\end{array}$ & $\mathbf{n}(\%)$ & $\mathbf{n}(\%)$ & $\mathbf{n}(\%)$ \\
\hline Lymphangioinvasion positive & $35(24.6)$ & $17(25.8)$ & $18(23.7)$ \\
\hline Lymphangioinvasion negative & $107(75.4)$ & $49(74.2)$ & $58(76.3)$ \\
\hline Lymphangioinvasion undetermined & 14 & 7 & 7 \\
\hline
\end{tabular}

\begin{tabular}{|l|l|l|l|}
\hline Patients with $\mathrm{MTS}-\mathrm{pN}+$ & $75(52.8)$ & $50(75.8)$ & $25(32.9)$ \\
\hline Lymphangioinvasion positive, $\mathrm{pN}+$ & $27(19)$ & $16(24.2)$ & $11(14.5)$ \\
\hline Lymphangioinvasion negative, $\mathrm{pN}+$ & $48(33.8)$ & $34(51.5)$ & $14(18.4)$ \\
\hline Lymphangioinvasion undet., $\mathrm{pN}+$ & 13 & 6 & 7 \\
\hline
\end{tabular}

\begin{tabular}{|l|l|l|l|}
\hline Patients without MTS - pNO & $67(47.2)$ & $16(24.2)$ & $51(67.1)$ \\
\hline Lymphangioinvasion positive, pNO & $8(5.6)$ & $1(1.5)$ & $7(9.2)$ \\
\hline Lymphangioinvasion negative, pNO & $59(41.5)$ & $15(22.7)$ & $44(57.9)$ \\
\hline Lymphangioinvasion undet., pNO & 1 & 1 & 0 \\
\hline
\end{tabular}

$\mathrm{n}$ - number of patients, \% - relative percentage, $\mathrm{N}$ - number of patients in the evaluated group, MTS - metastatic involvement, $\mathrm{pN}+-$ histologically verified metastases in regional lymph nodes, pNO - histologically verified status without metastases in regional lymph nodes

making a decision regarding treatment strategy it is important to remember that a proper surgical intervention is still the most important treatment and treatment with radioiodine, TSH suppression, and external radiotherapy have adjuvant roles (1). Properly chosen initial surgery and following observation can achieve permanently cured state in $90 \%$ of the patients, it has a long term impact on recurrence and survival, reduces the risk of reoperation (12).

To inseparable part of thyroid gland surgery belong perioperative examinations, especially in cases of suspected thyroid cancer. Preoperative ultrasonography and FNAB can help us to make decisions concerning the extent of surgical intervention and intraoperative biopsy can coordinate further approaches of the surgeon (14). Preoperative ultrasonography identifies roughly half of regional LN found during the surgery and identifies suspect metastases in regional LN in $20-31 \%$ of cases (1). It is because LN are overlaid by thyroid gland tissue. The overall sensitivity reported for some of the suspicious ultrasound features in large-volume centres is $83-93 \%$ (15). FNAB sensitivity in experienced hands reaches $98.9 \%$ (16) and should be performed on all nodes $>10 \mathrm{~mm}$ and in the case of clearly benign ultrasonography appearance only on those larger than $15 \mathrm{~mm}$ or $20 \mathrm{~mm}$, respectively (1).

\section{CONCLUSIONS}

PTC is the most common oncological disease of the thyroid gland and its typical feature is good survival prognosis and high rate of regional metastases. When comparing metastatic involvement in the age groups of under and over
45 years, we have found statistically significantly higher incidence of metastatic involvement in the group of under 45 years compared to the group of over 45 years. We have also noted statistically significant higher incidence of metastatic involvement in patients with positive capsule infiltration and lymphangioinvasion. In patients with metastatic involvement we have also found the size of tumour $\geq 1 \mathrm{~cm}$ more frequently in all groups. Age under 45 years itself in our study does not correlate with less aggressive disease, to the contrary more aggressive disease correlate with positive capsule infiltration and lymphangioinvasion.

Actually the most effective treatment modality remains surgery and its aim is to eradicate the disease by primary intervention, to reduce the amount of incidental findings, the number of reinterventions, to avoid persistence, recurrence and to enable adjuvant oncotherapy.

\section{REFERENCES}

1. Haugen BR, Alexander EK, Bible KC, et al. 2015 American Thyroid Association Management Guidelines for Adult Patients with Thyroid Nodules and Differentiated Thyroid Cancer: The American Thyroid Association Guidelines Task Force on Thyroid Nodules and Differentiated Thyroid Cancer. Thyroid 2016; 26(1): 1-133.

2. Brierley JD, Panzarella T, Tsang RW, et al. A comparison of different staging systems predictability of patient outcome. Thyroid carcinoma as an example. Cancer 1997; 79(12): 2414-2423.

3. Teixeira G, Teixeira T, Gubert F, et al. The incidence of central neck micrometastasis disease in patients with papillary thyroid cancer staged preoperatively and intraoperatively as NO. Surgery 2011; 150(6): 1161-1167.

4. Patron V, Hitier M, Bedfert C, et al. Predictive factors for lateral occult lymph node metastasis in papillary thyroid carcinoma. Eur Arch otorhinolaryngol 2013; 270(7): 2095-2100. 
5. Bilimoria KY, Bentrem DJ, Ko CY, et al. Extent of surgery affects survival for papillary thyroid cancer. Ann Surg 2007; 246(3): 375-381.

6. Zaydfudim V, Feurer ID, Griffin MR, et al. The impact of lymph node involvement on survival in patients with papillary and folicular thyroid carcinoma. Surgery 2008; $144(6): 1070-1078$.

7. Hartl DM, Mamelle E, Borget I, et al. Influence of prophylactic neck dissection on rate of retreatment for papillary thyroid carcinoma. World J Surg 2013; 37(8): 1951-1958.

8. Lebolleux S, Rubino C, Baudin E, et al. Prognostic factors for persistent or recurrent disease of papillary thyroid carcinoma with neck lymph node metastases and/or tumor extension beyond the thyroid capsule at initial diagnosis. J Clin Endocrinol Metab 2005; 90(10): 5723-5729.

9. Links TP, van Tol KM, Jager PL, et al. Life expectancy in differentiated thyroid cancer: a novel approach to survival analysis. Endocr Relat Cancer 2005; 12 (2): 273-280.

10. Sičák $M$, Sojak J, Slaštan $M$, et al. Papilárny karcinóm štítnej žlazy: Analýza vel'kosti primárneho tumoru, infiltrácie puzdra štítnej žlazy a lymfangioinvázie vzhl'adom k lokoregionálnemu metastázovaniu a veku. Otorinolaryng a Foniat (Praque) 2016; 65(4): 224-231.
11. Takami H, Ito Y, Okamoto T, et al. Therapeutic strategy for differentiated thyroid carcinoma in Japan based on a newly established guideline managed by Japanese Society of Thyroid Surgeons and Japanese Association of Endocrine Surgeons. World J Surg 2011; 35(1): 111-121.

12. Carling T, Carty SE, Ciarleglio MM, et al. American thyroid association design and feasibility of a prospective randomized controlled trial of prophylactic central lymph node dissection for papillary thyroid carcinoma. Thyroid 2012; 22(3): 237-243.

13. Esnaola NF, Cantor SB, Sherman SI, et al. Optimal treatment strategy in patients with papillary thyroid cancer: a decision analysis. Surgery 2001; $130(6)$ : 921-930.

14. Guevara N, Lassalle S, Benaim G, et al. Role of frozen section analysis in nodular thyroid pathology. Eur Ann Otorhinolaryngol Head Neck Dis 2015; 132(2): 67-70.

15. Cairncross L, Panieri E. Pre-operative diagnosis of thyroid cancer: clinical, radiological and pathological correlation. S Afr J Surg 2013; 51(2): 46-49.

16. Ito Y, Uruno T, Nakano K, et al. An observation trial without surgical treatment in patients with papillary microcarcinoma of the thyroid. Thyroid 2003; 13(4): 381-387. 